NBER WORKING PAPER SERIES

\title{
IS RETIREMENT DEPRESSING?: LABOR FORCE INACTIVITY AND PSYCHOLOGICAL WELL-BEING IN LATER LIFE
}

\author{
Kerwin Kofi Charles \\ Working Paper 9033 \\ http://www.nber.org/papers/w9033 \\ NATIONAL BUREAU OF ECONOMIC RESEARCH \\ 1050 Massachusetts Avenue \\ Cambridge, MA 02138 \\ July 2002
}

I wish to thank Robert Barsky, Rebecca Blank, John Bound, Ronald Ehrenberg, Olivia Mitchell, Matthew Shapiro, Gary Solon, Melvin Stephens, and Robert Willis, and seminar participants at the University of Michigan Labor Seminar, the IRP Summer workshop at the University of Wisconsin, Boston College, and Brown University for their comments and suggestions. They bear no responsibility for errors which remain. The author also gratefully acknowledges support from the National Institute of Health. The views expressed herein are those of the author and not necessarily those of the National Bureau of Economic Research.

(C) 2002 by Kerwin Kofi Charles. All rights reserved. Short sections of text, not to exceed two paragraphs, may be quoted without explicit permission provided that full credit, including (C) notice, is given to the source. 
Is Retirement Depressing?: Labor Force Inactivity and Psychological Well-Being in Later Life Kerwin Kofi Charles

NBER Working Paper No. 9033

July 2002

JEL No. I310, J140, J170, J260

\begin{abstract}
This paper assesses how retirement - defined as permanent labor force non-participation in a man's mature years - affects psychological welfare. The raw correlation between retirement and well-being is negative. But this does not imply causation. In particular, people with idiosyncratically low well-being, or people facing transitory shocks which adversely affect well-being might disproportionately select into retirement. Discontinuous retirement incentives in the Social Security System, and changes in laws affecting mandatory retirement and Social Security benefits allows the exogenous effect of retirement on happiness to be estimated. The paper finds that the direct effect of retirement on well-being is positive once the fact that retirement and well being are simultaneously determined is accounted for.
\end{abstract}

Kerwin Kofi Charles

408 Lorch Hall

Department of Economics and Ford School

University of Michigan

611 Tappan Street

Ann Arbor, MI 48109

and NBER

kcharles@umich.edu 


\section{Introduction}

\subsection{M otivation}

Economists believe that people's decisions are the product of constrained utility maximization - the effort to make themselves as happy as possible given the impediments they confront. While successful at describing a wide range of outcomes, this formulation is most often applied indirectly by economists, who typically study people's actions and rarely directly study satisfaction or "happiness". By contrast, in a large and informative literature, psychologists and psychiatrists routinely analyze happiness and attempt to identify the outcomes with which is correlated. This paper assesses the effect of labor force withdrawal in later life on happiness - or subjective well being (S.W.B.) as it is often called in the academic literature. This question has not been previously studied in the large and growing literature on the economics of retirement. Also, because the paper aims to tease out the magnitude of any causal relationship ${ }^{1}$ between retirement and happiness rather than to ascertain how the variables are correlated, the empirical methods employed differ markedly from those of most psychologists who have looked at this issue.

The question addressed in the paper is important for a number of reasons. First, as the population ages and moves in record numbers out of the labor force and into retirement, knowledge about how this universally experienced life change affects variables other than wealth, income and consumption - the usual focus of economists becomes increasingly vital. Also, the attractiveness of public policy initiatives which cause people to either delay or move forward their retirement is likely to be affected by information on what retirement does to psychological welfare. Second, despite the recent outpouring of research by economists on different questions related to health, analysis of aspects of mental well being has not continued apace. This paper may therefore be read as an initial effort to fill an important void in the economics of health literature. Third, given that the notion of "happiness" permeates nearly all formal economic modeling, a research effort which examines the link between well being and a choice variable of broad interest to economists represents a rare attempt by economists

\footnotetext{
${ }^{1}$ The importance of research on S.W .B. which allows causal inferences to be drawn has been noted by $E d$ Diener, one of the world's foremost experts in the study of SW B, who remarks in the abstract of a recent review article that the further evolution of research in psychology on S.W.B. requires "...go(ing) beyond correlations to understand(ing) the causal pathways leading to happiness..". He argues too that these causal relationships must be, "examined through more sophisticated methodologies" than those which have heretofore been used.
} 
to see whether people's actions cause them to actually feel the way our models predict they should.

Previewing the results, I find that retirement - defined as apparently permanent labor force non-participation in a man's mature years - is negatively correlated with well being. But because people with idiosyncratically low well-being, or people facing transitory shocks which adversely affect well-being might disproportionately select into retirement, it is not clear that this relationship is causal. Retirement and well being may be simultaneously determined, rendering it impossible for O.L.S. or simple panel estimates to tease out the causal effect of one of the variables on the other. Discontinuous retirement incentives in the Social Security System, and changes in laws affecting mandatory retirement and Social Security benefits allows the exogenous effect of retirement on happiness to be estimated. The paper finds that the direct effect of retirement on well-being is positive.

\subsection{Subjective W ell B eing ${ }^{2}$}

Research in psychology on subjective well being seeks to determine whether people live their lives in positive ways, and why they do or do not (Diener (1984), Diener (1999), Wilson (1967)). Psychologists have taken the approach that the best way to measure SW B or one of its components, such as sadness or boredom, is to ask people direct questions. ${ }^{3}$ Increasingly, questions such as those used by psychologists may be found on some of the large survey data sets used by economists. Typically called "depression scale" questions, they measure aspects of well being such as how happy people are or have recently been, or how depressed or sad. The idea behind all of these questions is that people who feel well about their lives will generally say that they do, and will report experiencing more positive than negative emotions. Reassuringly, these measures remain relatively constant for the same individual over time; are very stable within a society; and move, for an individual, in the direction one would predict after events such as the death of a loved one. Over the past three decades, a large research effort has

\footnotetext{
${ }^{2}$ The work in this section relies heavily on the two excellent survey articles by Diener (1984 and 1999)\}

${ }^{3}$ For example, the popular single item instrument of A ndrews and W ithey (1975) asks people how they "feel about their lives as a whole". Other instruments, such as that by K amman and Flett (1983) ask multiple, scored, questions: how often does the person smile; and whether, as far as the respondent is concerned, "nothing seems fun anymore".
} 
been directed at determining the correlates of positive SW B. Scholars have established, for example, that marriage is associated with positive SWB, as is good physical health. Also, more income has been found to have only a modest positive effect on well being and in some cases greater income has been associated with lower happiness. ${ }^{4}$

The relationship between retirement and well being has long interested psychologists both theoretically and empirically. There are two conflicting theoretical notions in the literature about how retirement ought to affect well being. The argument that the effect is likely adverse emphasizes the central role which work plays in the life of the typical adult (Henry (1971) and Miller (1965)). Retirement, which brings an end to this important work role, means that the retiree is likely to suffer psychologically from no longer being able to view himself as a productive, contributing member of society. Also, how can the retiree avoid boredom, given all the free time retirement brings? The argument for why retirement can be positive for well being emphasizes the negative aspects of work, and the importance of other, enjoyable roles that people play (Atchley, 1971, 1993). Nadler et. al. (1997) also make the interesting point that retirement, while clearly the event which marks the end of the work life, also marks the important achievement of having contributed to society for a substantial length of time - something which may well make well being higher.

Empirical work by psychologists on the effect of retirement usually either looks at differences between the retired and non-retired at a point in time or follows a sample of mature men and women over time as they pass through retirement. ${ }^{5}$ Most of these studies identify a negative association between retirement and psychological well being. F or example, Bosse et al. (1987) find that retirees report lower life satisfaction than workers. Portnoi (1983) finds that retirement is associated with depression, and Seiden (1981) finds, provocatively, that retirement may be associated with elderly suicide - a clear indication of life dissatisfaction. Kutner et al. (1956), Atchley and Robinson

\footnotetext{
${ }^{4}$ E conomist Robert Frank argues in his book "Luxury Fever" that a possible explanation for this result is that happiness is relative; if someone's income rises, but that of other people to whom he compares himself rises by an equal amount, then the first person personal well being will not rise.

${ }^{5}$ There has also been work on the effect of non-work more broadly defined on well being. This work does not address retirement per se, but examines instead how people fare psychologically when they are not working. J ohada (1982), for example, finds that people are negatively affected psychologically when they are unemployed. The unemployed, unlike the retired, are labor force participants, so the it is not at all clear how informative these results should be about the effect of permanent labor force withdrawal from the labor force.
} 
(1982), de Grace, J oshi, et al. (1994) and many others find evidence that retirement is associated with lower well being in cross section type models.

But there is also limited evidence that retirement may be good for well being. Mindanik et al. (1995), study a sample of about 600 elderly members of the Northern California H.M.O. over two surveys. They find that those who retired were less stressed than those who were not; were more likely to exercise; and were less likely to classify themselves as depressed. Matthews, Brown, Davis and Denton (1982) find that people rate retirement as the least stressful of a series of 34 events. J ackson et al. (1993) find that blacks in a longitudinal study experience an increase in their well being after retirement. Crowley (1985) finds that retirement does not appear to adversely affect well being, and other scholars such as Pallmore, Fillenbaum and George (1984) find inconclusive results.

Not only is the evidence regarding the empirical association between well being and retirement mixed, but the empirical strategies employed by previous authors make it quite difficult to draw causal inferences about retirement's effects - the key question from a policy perspective. The main problem is that most previous work has failed to isolate independent variation in retirement status. Thus, it is not possible to say with any reasonable degree of confidence whether a negative association between being retired and well being arises because people whose well being is idiosyncratically low are more likely to retire, or whether the process of retiring from the labor force causes well being to fall. In the next section, after having briefly described retirement in a utility maximizing framework, I present the strategies used in this paper to isolate exogenous variation in retirement status. Section 3 discusses the data and measurement issues. Section 4 presents the results and Section 5 concludes.

\section{F ramework and M otivation for E mpirical Strategy}

\section{$2.1 \quad$ Retirement and W ell Being}

Suppose that an individual's subjective well being at a point in time $t$, if he is of age $A_{\text {it }}$ is $M_{\text {it }}$, where

$$
M_{i t}=b_{r} R_{i t}+b_{A} A_{i t}+b_{x} X_{i t}+d_{t}+e_{i t} \text {. }
$$

\footnotetext{
${ }^{6}$ A nother, less important, problem is that many researchers have used very small, and potentially nonrepresentative samples in their empirical analyses. Some papers use only a few dozen observations.
} 
$R_{i t}$ is an indicator variable which equals 1 if the person is retired at time t. $A_{i t}$ is age at time $t$ and $x_{i t}$ is a vector of other observable individual controls which likely affect subjective well being. The mean-zero error $e_{i t}$ summarizes the set of latent factors which determine S.W.B, and $d_{t}$ an indicator variable for time period $t$. The coefficient $b_{r}$ in (1) is the causal effect of retirement status on SW B and its estimation is the desideratum of this paper.

In this paper, "retirement" refers to the state of the world in which a man who was previously an active labor force participant has permanently ceased being so. Because even someone who has been made to leave one job may remain a labor force participant by actively seeking new work, retirement as used in this paper is voluntary, though it is surely mediated by financial and other inducements. Note, defining retirement as coincident with being out of the labor force is only sensible for mature men. A person of age $A_{i t}$ has expected utility from continuing to be a labor force participant on one hand and from retiring on the other, of $u_{i t}$, and $U_{i t}$, respectively. He is retired as of age $A_{i t}$ if and only if $U_{\text {it }}-u_{i t} \geq 0$, where the difference $R_{\text {it }}^{*}\left(A_{i t}\right)=U_{i t}\left(A_{i t}\right)-u_{i t}\left(A_{i t}\right)$ is his desire to be retired at the time, and may be written

$$
R_{\text {it }}^{*}=g Z_{\text {it }}+v_{\text {it }} \text {. }
$$

$Z_{i t}$ and $v_{i t}$ are, respectively, the observed and unobserved determinants of expected utility, and $\mathrm{E}\left[\mathrm{v}_{\mathrm{it}}, \Gamma_{\mathrm{it}}\right]=0$.

Because people will only retire if $R_{i t}^{*}\left(A_{i t}\right)>0$, regressions performed on (1) will only yield unbiased estimates of $b_{r}$ in the unlikely event that the unobserved determinants of SWB are completely unrelated to the latent determinants of the desire for labor force withdrawal. The variable $v_{i t}$ includes factors such as the frustrations of the daily commute to work; the drudgery of sitting through staff or department meetings; the stress caused by working under deadlines; and the sense of achievement

\footnotetext{
${ }^{7}$ Of course, we can never know whether someone has permanently stopped doing anything as of the time he is observed in a survey, so long he continues to live beyond the date he is observed. At best, we may say that the person's actions (or inaction in the case of work) make it appear that he is unlikely to resume the activity in question.

${ }^{8}$ R etirement properly belongs to the class of dynamic optimization problems, and authors such as Stock and W ise (1990) provide very rigorous analyses of the retirement decision which carefully describe the nature of the optimization problem. My goal here is simply to present a framework which captures the elemental ingredients of any economic model of retirement.
} 
associated with making a positive contribution to society. Clearly, how pleasant or unpleasant any of these things makes the prospect of continued labor force participation in the mature years is likely to depend importantly on aspects of one's psychological make-up summarized in (1) as $e_{i t}$. Moreover, it is difficult to sign the endogeneity bias caused by correlation between the latent costs of work and the idiosyncratic component of SWB: people who have a very high distaste for continued work could either be those whose good cheer is incompatible with market work, or those whose generally morose nature makes the normal stresses of work unbearable.

Success at obtaining an unbiased estimate of $\beta_{r}$ requires isolating variation in retirement status which is independent of $v_{i t}$ and $\varepsilon_{i t}$. In this paper, this variation comes from the different age-specific retirement incentives and constraints which potential retirees face, and changes in these age-specific incentives and constraints over time. Below, I describe these sources of independent variation more fully and briefly describe the estimation strategy.

\subsection{Exogenous $\mathbf{V}$ ariation in $\mathbf{R}$ etirement Probability}

Someone contemplating retirement must consider the "retirement environment" he confronts - those factors outside of his control which make retirement more or less attractive. I use features of this environment for A merican men and changes in it over time as the sources of exogenous variation in retirement probability. I focus on the Social Security system and the elimination of mandatory retirement rules from the workplace.

Social Security Retirement benefits are the largest source of retirement income for mature A mericans. As such, we might expect that retirement decisions are affected by the characteristics of the program: Social Security retirement benefits are an increasing function of the age at which the person chooses to withdraw from the labor force. But, very importantly for our purposes, the marginal increase in benefits which the potential retiree receives by delaying retirement by an additional year is not constant across all ages.

Ever since the early 1960's, people have not been eligible for retirement benefits at all before age 62, the early retirement age. If retirement is delayed until the "normal retirement age" of 65 , the retiree receives "full" benefits which exceed by a

\footnotetext{
${ }^{9}$ See Fields and Mitchell (1984) for an analysis of the effect of changes in Social Security eligibility on retirement.
} 
significant amount the levels enjoyed by early retirees. Each additional year that retirement is delayed beyond age 65 brings a premium above the level of full benefits. People receiving Social Security benefits have always been able to continue working if they desire but, beyond exempt amounts, each dollar earned has meant a reduction in the amount of Social Security benefits the person can receive by a certain tax rate. The exemptions and tax rates together constitute the earnings test, and the magnitude of this test changes depending on whether the person's minimum age at retirement is 62 , 65,70 or 72 .

The way that retirement benefits are dispersed under Social Security means that there are large, discreet jumps in the financial incentives to retire when a person reaches one of these explicitly enumerated ages. Assuming that these incentives matter in the retirement decision, we could write the linear probability equation describing retirement in any time period as

$$
R_{i t}^{*}=d_{t}+a_{1} Z_{i t}+a_{2} A_{i t}+a_{3} A_{i t}^{2}+a_{4} A_{62}+a_{5} A_{85}+a_{6} A_{70}+a_{7} A_{72}+v_{i t} \text {, }
$$

where $A_{62}, A_{65}, A_{70}$ and $A_{72}$ are binary variables indicating that the person, in year $t$ is at least the age in the particular suffix. Now, even if there are age and time effects in individual well being equation such as (1), there is no reason whatever to suppose that there are discreet changes in well being at the these four enumerated ages, unless those changes in well being derive the effect of having reached those ages on the probability of retirement. In other words, equation (3) can be viewed as a first stage regression in a Two Stage Least Squares (TSLS) system, in which (1) is the structural equation for well being and the four indicator variables $A_{62}, A_{65}, A_{70}$ and $A_{72}$ are instrumental variables which affect retirement status, but do not separately enter the well being equation.

$M$ any have speculated about the reasons for the changes in retirement behavior between the 1970s and the 1980s; ${ }^{10}$ less emphasized has been the fact there were changes in the retirement environment between the 1980's and 1990's which could have been expected to differentially affect the retirement propensities of people of different ages, over the decade spanning those changes. ${ }^{11}$

\footnotetext{
${ }^{10} \mathrm{P}$ arsons (1984) is a good example

${ }^{11}$ Quinn (1998) provides an excellent summary of some of the more important factors which probably affected the retirement choices of the elderly over the past few decades, including the shift in private sector firms towards defined-contribution (pension plans with few - if any - age disincentives), and away from defined-benefit plans (with their traditionally large age-specific work disincentives)
} 
In the early 1980's, with concern about the future solvency of the Social Security System growing in the public consciousness, President Reagan appointed a commission to review the retirement program, and to recommend changes which would enhance the prospects for its future survival. As a result of the committee's work, some important adjustments to the system were enacted and signed into law as the Social Security A mendment of 1983. All of the important changes wrought by the legislation were designed to encourage more work in later life, and all were explicitly age-specific. The most basic way that the Amendment affected benefit levels was by changing the penalties and credits for persons starting to draw benefits at ages other than the normal retirement age. Table 1 shows that the penalty suffered for people who chose to begin collecting benefits early rather than at age 65 , was, in general, larger for every initial collection age after the passage of the law (the early 1990's) relative to the preA mendment period of the early 1980's. For people whose initial collection age was larger than 65, benefit levels were uniformly higher in the early-1990's than they were in the early-1980's.

The A mendment also affected the earnings test, and did so differentially for beneficiaries of different ages. For recipients aged 70 and 71 , the earnings test was abolished completely by the early 1990's, where there had once been an exemption of about $\$ 500$ a month. For younger recipients, there were exemptions both before and after the law change, but the relative level of the exemption got much lower for very young beneficiaries relative to people at age 65 or slightly older. Also, the table shows that the A mendment raised the marginal penalty which very young beneficiaries suffered for continuing to work, and lowered it for most workers at or above age 65. So whereas before the law, all recipients lost $\$ 1$ dollar in benefits for every $\$ 2$ in labor earnings above the relevant exemption, in the early 1990's after the passage of the A mendment, the rate on the people less than 65 remained at one-half, but fell to onethird for people above age 65, except for people age 72 or older who have never been subject to an earnings test. The A mendment could be expected to raise the labor supply of potential retirees of all ages, but because most of the changes more harshly penalized younger retirees, retirement for the oldest retirees should have become relatively more likely over the decade.

The effect of the Social Security Amendment on retirement probability is captured in a linear probability equation given by 


$$
\begin{array}{r}
R_{\text {it }}^{*}=d_{t}+a_{1} Z_{i t}+a_{2} A_{i t}+a_{3} A_{i t}^{2}+a_{4} A_{62}+a_{5} A_{65}+a_{6} A_{70}+a_{7} A_{72} \\
a_{8}\left(A_{62} * L\right)+a_{9}\left(A_{65} * L\right)+a_{10}\left(A_{70} * L\right)+a_{11}\left(A_{72} * L\right)+v_{i t}
\end{array}
$$

where $L$ is a binary variable denoting the time period after the A mendment had been passed and (4) is estimated on data which spans both the pre-Amendment and postA mendment time periods. Equation (4) also neatly captures the age-specific effects of the federal effort to outlaw mandatory retirement rules in the workplace, as this effort occurred at around the same time as the changes in Social Security and also had an explicit age-specific character. ${ }^{12}$ U sing the same reasoning as above, equation (4) is a first stage regression in a TSLS model in which the last eight terms are the excluded instruments, and the structural equation for well being is (1). This second identification method- while retaining the variation arising from discontinuous incentives provided by Social Security Rules for different ages at a point in time - estimates an unbiased estimate of the causal effect of retirement on S.W.B. by comparing: (a) the relative well being of mature people in different age categories before the A mendment to (b) the relative well being of people in those age categories at a point in time after the changes in Social Security and mandatory retirement take effect.

A variant of the first stage regression, which does not emphasize the discontinuities which occur at particular ages, argues merely that the A mendment should have caused people separated in age by only a very few years to face relative very different retirement incentives in the pre and post-Amendment periods. Thus, the relative retirement probability of people only a few years apart should have changed exogenously as a result of the A mendment. A part from the effect of the A mendment on retirement, there is no reason why the relative well being of people separated in age by as little as a year should have been different between the pre and post-A mendment time periods, once age and time effects have been accounted for. An alternative estimation strategy uses the first-stage regression

$$
R_{i t}^{*}=a_{1} Z_{i t}+a_{2} \sum D_{A}+d_{t}+a_{3}\left(\sum D_{A} * d_{t}\right)+v_{i t} .
$$

\footnotetext{
${ }^{12}$ Given the requirements of the A ge Discrimination in Employment Act (A.D.E.A., P.L 90-202; Dec. $15,1967)$, retirement rules in employment were legal prior the late 1970's, so long as the rule did not mandate retirement by age 65. Then three amendments to the Act were passed in 1974, 1978 and 1986 which respectively: extended the protections of the law to people employed in the federal sector; raised the minimum mandatory retirement age for private sector workers from 65 to 70 and eliminated such rules entirely for all federal workers; and eliminated such rules entirely for all private-sector employees. The age specificity of the various A mendments, and the staggered manner in which they were applied meant that the change in the possibly of being covered by mandatory retirement law between the early 1980's and early 1990's was different for mature workers of different ages.
} 
In (5), $D_{A}$ is a set of dummy variables referring to each age between 60 and 79 , and the interaction terms $D_{A} * d_{t}$ excluded from the structural equation for well being. The problem with is method relative to (3) and (4) is its requirement the relative well being of people separated in age by one year should have stayed constant between the early 1980's and early 1990's, except for the effect of the passage of the A mendment and the elimination of mandatory retirement laws. This assumption seems harsher than those required of the other two estimators. Nonetheless, I present these results below as well.

Finally, I attempt to isolate exogenous variation in "current" retirement status by using information of previous personal exposure to a mandatory retirement rule on a job held in the past. Specifically, I estimate a TSLS model of the effect of retirement on well being where

$$
R_{i t}^{*}=a_{1} Z_{i t}+a_{2} A_{i t}+a A_{i t}^{2}+d_{t}+a_{4} C+v_{i t}
$$

is the first stage regression. In (6), $C$ is a binary variable which equals 1 when the person was covered by a retirement rule at whatever job he held several years before period $t$. The identify assumption in (6) is that previous coverage by a retirement law by one's at a time in the past is not systematically related to current well being, except through its effect on current retirement.

The implicit identifying assumption in the model above is that workers take jobs when they are young with little attention paid to characteristics of those jobs which are only relevant when the worker is older many years later. Thus, at the start of the worklife, future well being should be unrelated to whether there is a retirement plan on the job or not. However, we do not have information of people's job characteristics at the start of their careers. Instead, we know whether they are covered by a retirement rule several years after they have started working, but more than a decade before the time that we examine their retirement. Should job characteristics at this time still be systematically unrelated to future well being, given that as they age, workers with strong labor force attachment and high well being may be expected to sort systematically into jobs without mandatory retirement laws?

We argue that this should be true. For one thing, sorting takes time. A worker has to spend some time learning about the characteristics of the current job, and needs time to identify jobs with characteristics he desires. In addition, people procrastinate. Given this seemingly universal tendency, the further back one moves from age the age at which retirement is studied, the less likely it is that people will have taken the steps 
necessary step of leaving a job will, after all, only become undesirable years later. ${ }^{13}$ Finally, there is the matter of uncertainly. Leaving a job is a costly thing, so we would expect that people who do it in a systematic fashion so as to avoid retirement rules would have to know with some level of certainty that, in the future, they would still want to work beyond the ages stipulated in the firm's retirement law. Many people who end up enjoying labor force participation at some age will not have known at all, or will not have known with sufficient confidence, that they would feel this way years before.

But even if previous coverage by a mandatory retirement rule at a job is not systematically correlated with current S.W.B. in some unseen way, why should previous coverage affect current retirement, particularly given that many types of retirement laws were no longer legal in the time period studied? The main explanation has to do with the incentives of firms. A firm which, when free to choose, elects to have a retirement rule, does so because this is its most preferred option. If these rules become illegal, as occurred in the time period I study, then the firm will simply move on to the next best thing. Almost surely, this next best thing should do something similar to what the retirement rules did - that is, cause people employed at the firm to be more likely to be retired than is true for similar people at other firms, even though retirement rules are forbidden. Firms may either use "carrots" (a nicer pension, generous retirement privileges); or sticks (bad assignments; unwelcome environments) to get people to retire, but there is no theoretical reason to suppose that, on average, firms will prefer one of these approaches over the other. So even if the firm's method of getting people to leave affected well being through some mechanism other than the direct channel of retirement, there is reason to think that in a random sample, carrot and stick approaches may cancel so that there should be no systematic relationship between what we might call the "encouraged-retirement mechanism" and the workers' current well being except insofar as current retirement is affected.

The next section discusses the data used to implement the various estimators descried above. I also describe how I measure S.W.B. in this paper. I then present my results, discuss them, and conclude.

\footnotetext{
${ }^{13}$ Some evidence in support of these two claims is forthcoming from the interesting work of Mitchell (1988) who analyzes what mature workers know of their firms' pension plans. A large number of people know nothing or are completely misinformed about their pensions in M itchell's data. M en in particular, had poor pension knowledge. This argues strongly against the idea that people learn about and sort themselves into jobs based on the retirement benefits jobs provide.
} 


\section{Data and M easurement I ssues}

\subsection{Data Sources}

To implement the estimators outlined in Section 2, information is needed on the labor force status and well being of people at ages which span those in what we will call the retirement interval - people in their 60's and $70^{\prime} \mathrm{s} .{ }^{14} \mathrm{Also}$, in order to exploit variation arising from the 1983 Amendment, this information should span the time when its changes took effect. The estimator which uses previous mandatory retirement coverage requires information both about retirement and mental health at a point in time, and about whether the same individuals were personally covered by a mandatory retirement rule at some previous time period. I use three sources of data in the analysis. One provides data on people in their 60's in the early 1990's; the second samples people in their 70's in the early 1990's and the third yields information in people in their 60's and 70 's in the early 1980's.

The Health and Retirement Study (H.R.S.) is a nationally representative panel data set which, beginning in the early 1990's, samples people who born between 1931 and 1941 and their spouses. In the analysis, I use a sample of men from the second and third waves ${ }^{15}$ of the data, with the restriction that the respondents are at least 60 years old in each wave, but less than 67 (69) in wave 2 (3). This maximum age restriction was imposed to because of the possibility that men who were much older than their wives in any year might differ from the rest of the population with respect to well being in some non-random way. ${ }^{16}$

The Survey of Asset and Health Dynamics among the Oldest Old (AHEAD) data set is jointly administered with the HRS. It is a panel data set - also begun in the early 1990's - which bi-annually samples households in which at least one person aged between 70 and 80 in 1991 resides. I use the first two waves of these data, drawn in 1993 and 1995, and restrict the sample to people who are less than 80, but who were no more than 5 years younger than the minimum age-eligible age in the year they were surveyed.

\footnotetext{
${ }^{14} \mathrm{Men}$ at least 60 years old meet the requirement of having been labor force participants for a protracted period. Men over 80 years old, if they survive that long, because of physical infirmity or convention are almost never serious labor force participants.

${ }^{15}$ I excluded W ave 1 from the analysis because the form of the well being questions in that wave was not the same as that in any of the other datasets used for any of the years studied.

${ }^{16}$ I ran the models presented below with these observations present, and all of the results were basically unchanged.
} 
The reason for the age exclusion is the mirror-image of that for the H.R.S; here the concern is that men who are much younger than their wives differ systematically with respect to well being and life satisfaction.

The National Longitudinal Survey of Mature Men (NLS-MM) is a panel data set, drawn from a representative sample of men aged between 45 and 59 in 1966 - the first year of that data was collected in this panel study. People were reinterviewed at varying intervals over the next 25 years. I use information on "current" retirement status and well being, from survey years 1981, 1983 and 1990. I use responses from a question in the 1969 survey which asked men whether the they were covered by a mandatory retirement law at the job they held in that year to determine personal previous coverage for men present in the sample in 1981 or 1983 . Only data from 1981, 1983 and 1990 were used in the well being analysis because this information was not elicited in the NLS-MM prior to that time. When pooled, data from the three sources meets the requirements of the three estimators.

The two variables "retirement" and "well being" raise important measurement issues. As mentioned previously, this paper treats retirement as apparently permanent labor force non-participation in mature years. Respondents on surveys may sometimes equate being "retired" with the receipt of Social Security benefits, or with the movement out of jobs they have long held. In either event, they may be labor force participants who self-classify as retired. To get around these issues, I define the binary variable "retired" to be equal to 1 when the respondent: (a) is not working for pay as of the survey date; (b) is not actively seeking work as of the survey date; and (c) has not worked for one year prior to the survey date. With respect to well being, all three of the data sources contain information of many measures of well being. However, for only two measures is there information in all of the data sources, and in all of the analysis years. These two are questions which assess whether the person has recently been "feeling depressed", and whether he has been "feeling lonely".

Table 2 summarizes the data. The first column presents the means for the combined sample which pools information from the three different data sources; the last three columns present the means for the separate data sources. Since I use more than one wave data from each of the panel data sources, these columns summarize the various data sets as of the first wave of those data used. The second-to last row shows that each of the data sources contributes significantly to the overall sample, with the relatively large contribution of the NLS data being due simply to the fact that I use 
more years data from this study than from the others. Over the years studied, the men in the pooled sample are well into their mature years, with an average age of 68 years old. Also, $67 \%$ of the person-year observations occur when the man is retired (permanently withdrawn from the labor force). Importantly, the table shows evidence of only smallest difference across the data sources in the incidence of the two negative mental well being measures. In wave 1 of the AHEAD data, there appears to be a slightly larger incidence of depression and loneliness. Because the AHEAD sample is older, it is not clear whether is an "AHEAD" effect, or an effect of age. In the empirical analysis, because there exist multiple waves of data for each data source, I am able to control for any effects which may derive from some unseen, and systematic feature of the particular data set.

There are some differences in the distribution of demographic characteristics across the three data sources, but these are likely due to differences in the age composition of the samples, and to the time period from which they are drawn. For example, the fact that a greater proportion of the AHEAD sample is white is in all probability the result of the fact that whites live longer than others, and the AHEAD is a representative sample of the oldest old. Similarly, that average education is lower for the NLS sample is because this data is representative of people in their 60's and 70's in the 1980's, while the HRS and AHEAD describe 60 and 70 year olds in the 1990's, and average education has risen over that interval. On the whole, the data appear ideal for answering the paper's question. In the next section, I present the results for the estimation of models presented previously.

\section{Results}

Table 3 presents O.L.S. and fixed-effects estimates of the effect of retirement on well being. Both sets of regressions are performed on the sample of 60 and 70 year olds, pooled across years and data sources. The standard errors in the O.L.S. regression are adjusted to correct for the fact that some individuals contribute more than a single observation to the analysis data. The O.L.S. results in the first column show that the effect of the control variables are of the same sign for the two well being measures, and are not surprising. Whites have better well being (recall that the well being measures depression and loneliness - are "bads"); the less educated seem to experience more depressed and more lonely feelings; and being married reduces depressed feeling and loneliness. Physical health appears to be a very important determinant of well being; 
people whose physical health is excellent rather than merely good or poor, display much higher well being. Of course, the variable of greatest interest is whether the person is withdrawn from the labor force - i.e., retired. There is a strong, statistically significant and adverse relationship between being retired and psychological well being for mature men for both of the well being measures

The second column of Table 3 presents the results of "within" estimates of the effect of retirement, wherein all of the variables in the model in the first column are replaced by the deviation from their individual-specific time mean. These regressions, which exploit the panel aspect of the data, analyze what the relationship is between the individual-specific change in retirement status and the change in well being over time. As is well known, all of the time invariant regressors vanish from these fixed effects models. Like the O.L.S. results, the panel data estimates of retirement's effects are suggest that retirement adversely affects well being. However, they are very imprecisely estimated and are much smaller than the O.L.S. results.

These two sets of regressions approximate quite closely previous empirical work on this subject, though with larger samples and more recent and nationally representative data. Because there is no plausibly exogenous variation in retirement status in the O.L.S. model depicted in the first column, it is possible that correlation between unseen aspects of well being and retirement status might be driving the results of the simple model. Fixed effects methods partially deal with this problem - but only partially - for they are purged of latent, fixed determinants of well being. Indeed, once these fixed, latent effects have been accounted for, the estimated effect of retirement on well being is much smaller than the O.L.S. case, suggesting that people with low levels of well being are disproportionately represented among people withdrawn from the labor force at any age. But, the panel estimates are not without problems. For one thing, the data used in this study cover a very short interval $(2$ years at most in H.R.S. and AHEAD). Thus, the changes in well being which a panel estimator is likely to identify are changes which are not steady state changes, but the immediate, transitory changes which occur over a very tiny window. Also, the panel model only controls for latent, fixed determinants of well being; there are also latent time-varying aspects of well being which might also be determinants of retirement status. Panel estimates are therefore subject to possible endogeneity bias as well.

Nonetheless, if well being is the same thing as economists' "utility", the similarity of the fixed-effects and O.L.S. results call into question the wisdom of economists' notion 
that people only choose to do things which make them better off. ${ }^{17}$ To know whether the effects identified to this point are illusory - that is, to isolate the true causal effect of retirement - I turn next to the models laid out in the previous section which, hopefully, isolate exogenous variation in retirement, and which also estimate the steadystate effects of retirement on well being.

The first set of estimates will rely on the discontinuous retirement incentive structure of Social Security and the changes in those incentives over the time period studied here. I earlier argued why there is good reason to presume that these instruments are unrelated to well being, except through their effect on retirement; whether they have a non-trivial effect on retirement remains has yet to be established.

As a first answer to this question, consider Figures 1 and 2. These figures show actual and predicted retirement rates in the early 1980's and early 1990's for the men in the sample. The predictions are from simple, linear regressions of retirement status on age. Both figures show the discontinuity in retirement status earlier discussed, though not as cleanly as the discussion suggests. In both time periods, retirement seems to jump up at around age 62, jump further at or around age 65, then drop somewhere between 70 and 72 . While the same overall retirement pattern is evident in both time periods, visual inspection of the graphs suggests that the magnitudes of the discrete changes suggests that the patterns are not identical. Moreover, note that the changes over time in retirement which are the fulcrum of part of the analysis below are changes in retirement, once other observables have been controlled for. No such controls are used in the graphs. The graphs help explain the intuition behind the TSLS estimators: I track well being around the discrete jumps in retirement which occur at any point in time; and compare the changes in well being which occur at any age-specific jump between the two time periods, and compare this change to that which occurs at a different age-specific jump across the two time periods.

An indication of the strength of the instruments is forthcoming from regressions such as those presented in Table 4. Retirement status is the outcome variable in these first stage regressions, and the instruments are those discussed in the previous section. Work by Bound et al (1995) and by Staiger and Stock (1997) shows that the use of an

\footnotetext{
${ }^{17}$ It should be pointed out there are economic arguments under which people choose something which brings them unhappiness. For example, retirement might be an individual-specific "experience good" (in the sense in which J ovanovic (1985) uses the term), about which one knows virtually nothing until one tries it. Then, people might choose to become retired, only to discover that it lowers well being.
} 
instrumental variables approach to deal with a potentially endogenous regressor may itself yield biased and inconsistent results if the instruments explain little of the variation in the endogenous regressor, even if there is only very small independent correlation between the instrument and the outcome variable of interest. They recommend that researcher focus on and report the $F$-statistics of the instruments in the first stage regression as a summary measure of the quality of the instruments used. I follow their recommendation in Table 4, which presents both the first stage regression results and the F-statistics for the various excluded instruments.

The first column shows the effect of age and a dummy for the time period after the passage of the Social Security Amendment in a linear probability model for retirement status which includes as controls an indicator variable indicating which of the three datasets the observation is from, a race indicator, a marital status indicator, an indicator for poor health, and a measure for the number of years of completed schooling. As is also evident in the graphs, being older has a positive effect on retirement probability, and, overall, retirement was more likely in the early 1990's than the early 1980's holding constant all observables. The second column asks whether there were differences in the change in retirement probability over the two time periods, for people of different ages. This effect is captured by a variable which is the product of the person's age and a binary variable which indicates whether the observation comes from the period after the Amendment. The age-era interaction term is strongly positive and strongly statistically significant, indicating that retirement became relatively more common between the early-1980s and early-1990s for people at older ages than those older. ${ }^{18}$

Under an assumption that there is no reason to suppose that the relative well being of mature people of different ages changed over time, once time effects had been accounted for - i.e., that the age-time period interaction does not belong in the well being equation - then the results in the second column would argue that the simple agetime period is a legitimate instrument for retirement status. There is a large F statistic on the test of the significance of the simple interaction, suggesting that it is not

\footnotetext{
${ }^{18}$ I also estimated linear probability model of retirement in which age was entered as a set of discrete dummies rather than as a linear term. The corresponding age-time period interactions are with this set of age dummies and a variable indicating the period after the passage of the A mendment. The results are broadly similar to those presented in the second column of T able 4: the change in retirement rates is relatively greater for older persons, and F-test show that these instruments are strong. These results are available upon request.
} 
a remotely weak instrument in the sense used by Bound and others. I present these results below, but argued earlier that the assumptions required to make this estimator credible, are strong. However unlikely, there might well have been different age-specific changes in well being between the early-1980s and early 1990s which over time which had nothing to do with retirement. For example, if treatment of the elderly over time in society at large worsened over the decade; if bad treatment causes well being to fall; and if the change in bad treatment over time was largest for the oldest old; then there would be a it would not be correct to assume that the relative well being of elderly people of different ages remains the same over time.

The next two columns of Table 4 show the results for the estimators which I believe are much easier to defend. The second column presents the results which measure the effect of the discontinuous Social Security incentives on retirement. These formally confirm the results hinted at in the graphs presented earlier. There are statistically significant upward jumps in retirement at the time when people become eligible for "early" retirement and full benefits. Also, when the earnings test is relaxed at around age 70 , there is a discrete fall in retirement probability. The large F statistics on these excluded instruments indicates that they have quite meaningful effects on retirement status. Again, there is no reason whatever to suppose that the well being for the elderly ought to change at these discrete nodes for any reason other than the effect of reaching these nodes on retirement.

The third column adds a set of (minimum)age-dummy, post-Amendment interaction terms. A gain, the ages come directly from the ages explicitly enumerated in the legislation. By examining changes over the period when the A mendment was passed, this regression exploits a second type of exogenous variation. Recall that the changes stipulated by the A mendment were designed to cause people to delay initial retirement, and to encourage elderly employment. The regressions show changes in retirement over time perfectly consistent with those modifications. People at older ages became relatively more likely to be retired, and the regression shows that this relative change over time also displayed discrete jumps at particular ages. This is a much sharper result that the simple age-era interaction depicted in the first column of the Table and again has the feature that there is no reason whatever to suppose that relative well being over time for people of different changes would exhibit discrete jumps corresponding exactly to the ages enumerated in a law in the middle of the relevant time 
period, unless that relative change was caused by a change in retirement wrought by the law.

One interesting aspect of all of the results in Table 4 is that the estimated sign on the indicator variable denoting the time period after the passage of the Amendment is positive in the regressions without any age, time period interactions, and are negative otherwise. The coefficient on the age-era interaction in column 2 answers the question: What was the change in retirement probability between the early 1980's and the early 1990's for people aged A in the two eras, relative to the change in retirement probability over the same interval for people aged $A+1$ in the two eras? When the interaction terms excluded from the retirement equation, the coefficient on the "post-A mendment" dummy variable is a weighted average of the true period effect (that is, the "postA mendment" effect), and the relative change over time for different ages. Since the results with the interactions show that there is a strong relative increase in retirement probability for people who are older, the coefficient on the "post-A mendment" dummy is too large in column 1 ; indeed it is of the wrong sign. Once the differential age effects are taken care of, there is actually evidence of a tiny decline in retirement probability over the interval. This is consistent with results from Quinn (1998).

Table 5 presents various TSLS estimates of the effect of retirement on well being using the discontinuous incentives as a source of variation. For the time being, focus on the results in the first row of the table. Column (I) of the table presents the results where the only excluded instruments are the indicator variables marking the four minimum ages enumerated in Social Security Rules. The IV results contradict the O.L.S. estimates, but are only weakly significant. Column (II) adds the minimum ageinteraction terms to the set of excluded instruments. Again, the IV estimates yield results completely at odds with the O.L.S. results in that retirement in these regressions appears to be associated with increases in well being, once exogenous variation in retirement probability has been identified. The effects appear to be particularly large for feelings of loneliness.

In the third column, I take on directly the notion that there might be discrete changes in well being at the explicitly enumerated ages which do not arise from the effect of having achieved these ages on retirement probability. Maybe reaching age 62 (or 65, 70 and 72) changes a person's self-concept in a way similar to what becoming 40 or 50 years old is rumored to do. To deal with this possibility, I add the four minimumage binary variables directly to the well being equation and use only the interactions 
between these variables and the indicator variable for the post-A mendment period as the excluded instruments. In no case is any of these dummies statistically different from zero in the well being equation. Moreover, using only the variation which derives from changes in retirement probability the TSLS results in the first row are almost identical to those in the other two columns.

The last column uses only variation in relative retirement probability over the time the Amendment was passed, and ignores the explicit age discontinuities. These results reproduce the results of the other columns in broad, though the estimated effects are smaller.

The strongest results in the first row of the Table are those which exploit changes over time in relative retirement probability. $Y$ et, can we be certain that the relative well being of people of different ages would have remained essentially the same over the time period studied, but for the effect of changes in Social Security and the elimination of mandatory retirement laws, as we must if the TSLS estimates are to yield unbiased causal estimates? Concern that this is not the case is largest when the age range of the people studied is large. For this reason, the last two rows of Table 5 present TSLS results where the age ranges of the men under study are restricted to 6069 and 70-79, respectively. Obviously, with these age restrictions, not all of the enumerated age dummies and interactions is present in every equation. For example, dummies $A_{70}$ and $A_{72}$ and their interactions are not present in the results in the first three columns for the sample which is in their 60's. Reassuringly, all of the results in the last two rows are quite similar to the results in the first row. This is particularly true for the sample of 60 year-olds. That the estimated effects for the 70 year-olds only are smaller and less precisely estimated than those for the entire sample is likely due to the fact that relative retirement incidence changed little for people in this age category. Most people in their 70's are retired, whatever time period one studies. While the A mendment may have made some people more likely to work, these were probably a small fraction of all 70 year-olds, so there is correspondingly not much exogenous variation in the explanatory variables. Despite this, the results for this age group tell essentially the same story as those in the rest of the table.

Most of the results in the table are large and highly statistically significant, and indicate that retirement is associated with an improvement in well being once the endogeneity of retirement status is accounted. This is perfectly consistent with the description of a voluntary retirement decision laid out in Section 2. People who choose 
to withdraw from the labor force, according to that discussion are those whose dissatisfaction with the idiosyncratic aspects of work is higher than those of their similarly aged counterparts who remain. Since a part of the intensity of their dissatisfaction has to do with how they feel in general, the people who retire will be disproportionately "depressed", hence the O.L.S. result. But the fact that people who are more depressed than their observationally identical counterparts are more likely to retire, does not imply that retirement does not bring happiness to even these people.

As a check on the results, I implement the second set of TSLS estimates which use personal coverage by a mandatory retirement rule in the job held in 1969 as the instrument for retirement status in 1981 or 1983 - a gap of 13 years on average. Table 6 presents the results of the first stage regressions. The F-statistic shows that previous personal mandatory retirement coverage has a tremendous amount of explanatory power on retirement even after the use of such rules was no longer legal. Notice also that the coefficients are virtually identical across the two specifications in the table, suggesting that coverage 13 years before is systematically unrelated to observable worker characteristics. While this is no formal proof that previous coverage is unrelated to latent worker characteristics, this last is nonetheless reassuring.

Table 7 presents the TSLS estimates with the personal previous coverage by a mandatory retirement rule as the excluded instrument. The first column presents the results with no controls (simple Wald estimates), and the second column presents results with observable controls. For both measures and for both sets of estimates, there are strongly statistically significant effects. A gain, retirement is associated with better well psychological well being once endogeneity has been accounted for. It is also reassuring that the estimated marginal effect of retirement is quite similar across the two sets of TSLS models.

The last set of result is subject to the criticism that previous coverage could be directly related to current well being - perhaps through such channels as sorting by workers or the treatment meted out by firms which previously had such rules after the rules are illegal. With respect to sorting, I believe this effect to be considerably mitigated by the fact that I look at retirement coverage more than a decade before the date retirement is observed. If one believes that sorting explains previous retirement coverage, then one would have to argue that people who know that they would not be happy ten years in the future with life outside of the work sorted themselves 
systematically into jobs ten years ahead of time where they are no retirement rules. Though possible, this seems improbable.

The idea that the results are driven by unseen behavior by firms which, net of the effect of such treatment on retirement probability, makes workers more happy is impossible to disprove, but there are arguments which can be marshaled which cut the opposite way. For one thing, there is no requirement that the acts firms undertake to make older workers quit is something which will bring workers pleasure; there is no economic reason whatever why firms might not, in fact, engage in acts to make workers quit which workers dislike. Also, so long as the firm is trying to get a worker who wants to continue working to quit, then whether the firm uses a carrot or a stick, it is possible that the fact that he is being or has been forced out, contrary to what he would have otherwise chosen, should make him feel badly. If either of these things is true then the bias in the TSLS estimates serves to strengthen the results presented here. Finally, the credibility of the both sets of TSLS results is strengthened by the fact that each yields results which confirm the other in broad outlines.

\section{Conclusion}

This paper assesses how retirement - defined as voluntary and apparently permanent labor force non-participation in a man's mature years -affects subjective well being. The simple correlation between well being and retirement status and well being is negative, as is that between the simple change in well being and the change in retirement status. But both of these may stem not from the fact that retirement lowers well being, but rather that both people with low well being, and people who experience negative and possibly transitory changes in well being may be more likely to retire. Isolating a causal, steady state effect requires isolating exogenous variation in retirement status.

I use several sources of such variation in the paper. First, I exploit the fact that Social Security Retirement incentives are discontinuous at explicitly enumerated ages. Second, legislative changes in Social Security eligibility rules and in the elimination of mandatory retirement laws could be predicted to cause changes in the relative retirement probability over time for people in very narrow age windows. Third, if a man is covered by a mandatory retirement rule at a time in the past when such rules were legal, his probability of retirement should be higher years in the future. Using a series of models which exploit these different sources of variation, I find that the simple 
estimates of retirement on well being are illusory; retirement appears to actually improve well being once the endogeneity of retirement is accounted for.

The topic this paper addresses has interested psychologists for some time, but has not been the focus of any research by economists. This lack of attention derives partly from the fact that economists rarely try to measure well being directly, and in part from the fact that most research in economics on retirement focuses on its causes rather than its effects. That an ever larger fraction of the population will be withdrawn from the labor force in the next few years creates an urgent need to gain a richer understanding of how this transition is likely to affect well being. Income, poverty status and other measures which typically interest economists surely affect well being (that, after all, is why we study them), but there is much to be gained from exploiting the direct information which is available about well being in newer data sources, and which is used routinely by psychologists and other scholars. 


\section{R eferences}

Angrist, J .D., Imbens, G.W . and Rubin, D.B. (1996), "Identification of Causal Effects Using Instrumental Variables", J ournal of the A merican Statistical A ssociation, 91.

A tchley, R. C. (1971), "Retirement and Leisure Participation: Continuity or Crisis?", The Gerontologist, 11, 13-17.

Atchley, R. C. (1993), "Continuity Theory and the Evolution of Activity in Later Life", in J . R. K elly (Ed.), A ctivity and A ging: Staying Involved in Later Life, Newbury Park, CA, Sage.

Atchley R. C. and Robinson, J. L. (1982), "Attitudes toward Retirement and Distance from the Event", Research on A ging, 4, 299-313.

B eck, A.T., Ward, C. H., M endelson, M., M ock, J . and Erbaugh, J. (1961), "An Inventory for Measuring Depression", Archives of General Psychiatry, 4, 561-571.

B eck, Scott H. (1982), "A djustment to and Satisfaction with Retirement", J ournals of Gerontology, 37 (5), 616-624.

B osse, R., Aldwin, C. M., Levenson, M. R., and Ekerdt, D. J . (1987), "M ental Health Differences among Retirees and W orkers: Finding from the Normative A ging Study", P sychology and A ging, 2, 383-389.

B ound, J, J aeger, D., and B aker, R. (1995), "P roblems with Instrumental V ariables Estimation When the Correlation B etween the Instruments and the Endogenous Explanatory Variable is W eak", J ournal of the A merican Statistical A ssociation, 90(430), 443-450.

B radburn, N. M . (1969), The Structure of P sychological W ell-B eing, Chicago: A Idine.

B ryant, F.B., and Veroff, J . (1982), "T he Structure of P sychological W ell-Being: A Sociohistorical A nalysis", J ournal of Personality and Social Psychology, 43, 653-673.

Burkhauser, Richard and Quinn, J oseph (1983), "Is M andatory R etirement Overrated? Evidence from the 1970s", J ournal of Human Resources,18, 337-358.

B urkhauser, Richard and Q uinn, J oseph (1997), Implementing Pro-W ork Policies for Older A mericans in the T wenty-First Century. Paper prepared for the United States Senate Subcommittee on A ging, F orum on Older W orkers, J uly 25. A Iso, B oston College Department of E conomics W orking Paper No.278.

Clark, A.E., and Oswald, A.J . (1994), "Unhappiness and Unemployment", E conomic J ournal, 104 ,

648-659. 
Crowley, J . E. (1985), "Longitudinal Effects of R etirement on M en's P sychological and Physical W ell-Being", in H. S. Parnes, J . E. Crowley, R. J . Haurin, L. J. Less, W. R. Morgan, F. L. M ott and G. Nestel (Eds.), Retirement among A merican M en, Lexington, MA, Lexington Books, 147-173.

Deiner, E. (1984), "Subjective W ell-B eing", P sychological Bulletin, 95, 542-575.

Deiner, E., E mmons, R., Larsen, R. and Griffen, S (1999). "T he Satisfaction W ith Life Scale," mimeo, University of Illionois at Urbana - Champaign.

Diener, E., Suh, E unkook M., Lucas, Richard E. and Smith, Heidi L. (1999), "Subjective W ellB eing: Three Decades of Progress", P sychological Bulletin, forthcoming in 1999.

de Grace, G. R., J oshi, P., Pelletier, R. and B eaupre, C. (1994), "Consequences Phychologiques de la Retraite en F onction du Sexe et du Niveau Occupationnel Anterieur", Canadian J ournal on A ging, 13, 149-168.

Ettner, $\quad$ S., Frank, R.G. and Kessler, R. C. (1997), "T he Impact of Psychiatric Disorders on Labor M arket Outcomes", J ndustrial and Labor Relations R eview, 51, 64-81.

Fields, Gary S. and Mitchell, Olivia S. (1984), "E conomic Determinants of the Optimal Retirement Age: An Empirical Investigation", J ournal-of-Human-Resources, 19 (2), 245-262.

Gall, T erry L., Evans, David R., and Howard, J ohn (1997), "T he R etirement Adjustment Process: Changes in the W ell-B eing of $M$ ale R etirees across Time", J ournals of $G$ erontology: Series B: Psychological Sciences \& Social Sciences, 52B (3), P 110-P 117.

Henry, W . E. (1971), "T he R ole of W ork in Structuring the Life Cycle", Human Development, 14, 125-131.

Imbens, G. W., and A ngrist J . D. (1994), "Identification and Estimation of Local A verage Treatment Effects", E conometrica,, 62, 467-476.

J ackson, J. S., Chatters, L. M., and Taylor, R. J . (1993), A ging in B lack A merica, Newburry Park, CA, Sage.

J ovanovic, B oyan. (1985), "J ob M atching and the Theory of T urnover", J ounral of Political Economy, 87(5), 972-990.

J ohada, M. (1982), Employment and Unemployment: A Social Psychological A nalysis", New Y ork, Cambridge University Press.

J ournal of Human Resources (1995), Special Issue on the Health and Retirement Study: Data Quality and Early Results, Richard Burkhauser and Paul Gertler (editors). 
K aestner, R. (1996), "A re B rother's R eally B etter? Sibling Sex Composition and Education A chievement Revisited", NBER Working Paper No.5521.

K utner, B., F anshel, D., T ogo, A., and Langer, S. (1956), Five Hundred over Sixty, R ussel Sage $\mathrm{F}$ oundation, New $\mathrm{Y}$ ork.

Matthews, A. M., Brown, K. H., Davis, C. K., and Denton, M. A. (1982), "A Crises A ssessment $T$ echnique for the Evaluation of Life E vents: Transition to Retirement as an Example", Canadian J ournal on A ging, 1, 28-39.

Midanik, Lorraine T., Soghikian, K., R ansom, Laura J ., and Tekawa, Irene S. (1995), "T he E ffect of R etirement on M ental Health and Health B ehaviors: The K aiser Permanente Retirement Study", J ournals of Gerontology: Series B: Psychological Sciences \& Social Sciences, 50B (1), S59-S61.

Miller, S. J . (1965), "The Social Dilemma of the A ging Leisure Participant", in A. Rose and W. Peterson (Eds.), Older People and Their Social W orld, P hiladelphia, F. A. Davis.

Mitchell, Olivia S., (1988) "W orker K nowledge of Pension Provision", J ournal of Labor Economics, 6(1), 21-39.

M oen, Phyllis (1996), "A Life Course Perspective on Retirement, Gender, and W ell-Being", J ournal of Occupational Health Psychology, 1 (2), 131-144.

M utran, Elizabeth and Reitzes, Donald C. (1981), "Retirement, I dentity and W ell-B eing: Realignment of Role Relationships", J ournals of Gerontology, 36 (6), 733-740.

Nadler, J odi D., Damis, Louis F . and Richardson, E mily D. (1997), "P sychosocial A spects of A ging", Handbook of Neuropsychology and A ging: Critical Issues in Neuropsychology, New Y ork, Plenum Press, 44-59.

Oswald, A.J . (1997), "Happiness and Economic Performance", E conomic J ournal, 107, 18151831.

Pallmore, E. B., Fillenbaum, G. G., and George, L. K. (1984), "Consequences of Retirement", J ournal of Gerontology, 39, 109-116.

Portnoi, V. A. (1983), "Postretirement Depression: Myth or Reality", Comprehensive Therapy, 9, 31-37.

Quinn, J . (1998), "R etirement Trends and Patterns in the 1990s: The End of an Era?", W orking Paper, B oston College. 
Q uinn, J oseph (1997), "T he R ole of B ridge J obs in the R etirement Patterns of Older A mericans", in Social Security and the Labour Market, P hilip deJ ong and Theodore M armor (editors), London, A shgate Publishing Ltd., 91-116.

Quinn, J oseph, Richard Burkhauser and Daniel Myers (1990), Passing the T orch: The Influence of Economic Incentives on W ork and Retirement, Kalamazoo, MI: T he W. E. U pjohn Institute for E mployment Research.

Ruhm, C. (1995), "Secular Changes in the W ork and Retirement Patterns of Older M en", J ournal of Human Resources, 30, 362-395.

Seiden, R. H. (1981), "M ellowing with A ge: Factors Influencing the Nonwhite Suicide Rate", International J ournal of A ging and Human Development, 13, 265-284.

Staiger, D., Stock J . (1997), "Instrumental variables R egression with W eak Instruments", E conometrica, 65(3), 557-86.

Stock, J ames H. and W ise, David A. (1990), "Pensions, the O ption Value of Work, and Retirement", Econometrica, 58 (5), 1151-1180.

W ilson, W . (1967), "Correlates of A vowed Happiness", P sychological Bulletin, 67, 294-306. 
Table 1. Effects of Social Security A mendment of 1983 on R etirement B enefits F or R ecipients of Different A ges In the Early 1980's and the E arly 1990's.

\begin{tabular}{|c|c|c|c|c|c|c|}
\hline \multirow[t]{2}{*}{ Age } & \multicolumn{2}{|c|}{$\begin{array}{l}\text { Fraction of "F ull Monthly B enefits" if } \\
\text { Receiving B enefits for First Time }\end{array}$} & \multicolumn{2}{|c|}{$\begin{array}{c}\text { Monthly Earnings Permitted } \\
\text { With No reduction in B enefits } \\
\text { (Exemption) }\end{array}$} & \multicolumn{2}{|c|}{$\begin{array}{l}\text { \$ R eduction in B enefits } \\
\text { for Each } \$ \text { of } E \text { arnings }\end{array}$} \\
\hline & Early 1980's & E arly 1990's & Early 1980's & Early 1990's & Early 1980's & Early 1990's \\
\hline$<62$ & $0 \%$ & $0 \%$ & & & & \\
\hline $62-64$ & $\begin{array}{l}\mathrm{F}-5 / 9 \% \text { per month } \\
\text { under age } 65\end{array}$ & $\begin{array}{l}F-5 / 9 \% \text { per month first } \\
36 \text { months under age } 65 . \\
\text { Then } 5 / 12 \% \text { for } \\
\text { additional months }\end{array}$ & $\$ 373.00$ & $\$ 59.00$ & $\$ 1$ for each $\$ 2$ & $\$ 1$ for each $\$ 2$ \\
\hline 65 & $F=100 \%$ & $F=100 \%$ & $\$ 458.00$ & $\$ 812.00$ & $\$ 1$ for each $\$ 2$ & $\$ 1$ for each $\$ 3$ \\
\hline $66-69$ & $\begin{array}{l}F+1 / 12 \% \text { per month } \\
\text { over age } 65 \text { and less } \\
\text { than } 72\end{array}$ & $\begin{array}{l}F+3 / 24 \% \text { per month } \\
\text { over age } 65 \text { for each odd } \\
\text { numbered year }\end{array}$ & $\$ 458.00$ & $\$ 812.00$ & $\$ 1$ for each $\$ 2$ & $\$ 1$ for each $\$ 3$ \\
\hline $70-71$ & $\begin{array}{l}F+1 / 12 \% \text { per month } \\
\text { over age } 65 \text { and less } \\
\text { than } 72\end{array}$ & $\begin{array}{l}F+3 / 24 \% \text { per month } \\
\text { over age } 65 \text { for each odd } \\
\text { numbered year }\end{array}$ & $\$ 458.00$ & No Limit & $\$ 1$ for each $\$ 2$ & \\
\hline$>71$ & $\begin{array}{l}F+1 / 12 \% \text { per month } \\
\text { over age } 65 \text { and less } \\
\text { than } 72\end{array}$ & $\begin{array}{l}F+3 / 24 \% \text { per month } \\
\text { over age } 65 \text { for each odd } \\
\text { numbered year }\end{array}$ & No Limit & No Limit & & \\
\hline
\end{tabular}

The information in this T able comes from various publications of the Social Security Administration, and from conversations with officials at the agency. 
Table 2. M eans of Selected V ariables, Overall and By Data Source

\begin{tabular}{|c|c|c|c|c|}
\hline Variable & Overall & HRS, 1994 & AHEAD, 1993 & $\begin{array}{c}\text { NLS-M M, } \\
1981\end{array}$ \\
\hline \multirow[t]{2}{*}{ Retired } & .68 & .49 & .83 & .67 \\
\hline & $(.46)$ & $(.5)$ & $(.37)$ & $(.47)$ \\
\hline \multirow[t]{2}{*}{ A ge } & 68.2 & 62.6 & 73.6 & 66 \\
\hline & $(5.6)$ & $(2.1)$ & (3) & $(4.2)$ \\
\hline \multirow[t]{2}{*}{ W hite? } & .79 & .78 & .88 & .74 \\
\hline & $(.41)$ & (.4) & (.3) & $(.44)$ \\
\hline \multirow[t]{2}{*}{ Schooling $<12$ Y ears } & .43 & .31 & .37 & .61 \\
\hline & $(.5)$ & $(.46)$ & $(.49)$ & $(.48)$ \\
\hline \multirow[t]{2}{*}{ Schooling $>12 \mathrm{Y}$ ears } & .28 & .37 & .33 & .16 \\
\hline & $(.45)$ & $(.48)$ & $(.47)$ & $(.4)$ \\
\hline \multirow[t]{2}{*}{ M arried } & .81 & .84 & .76 & .82 \\
\hline & $(.4)$ & $(.36)$ & $(.42)$ & (.4) \\
\hline \multirow[t]{2}{*}{ Health Excellent } & .17 & .18 & .13 & .25 \\
\hline & $(.37)$ & $(.38)$ & $(.33)$ & $(.4)$ \\
\hline \multirow[t]{2}{*}{ Depressed? } & .15 & .12 & .15 & .14 \\
\hline & $(.36)$ & $(.32)$ & $(.14)$ & $(.4)$ \\
\hline \multirow[t]{2}{*}{ Lonely? } & .12 & .10 & .13 & .11 \\
\hline & $(.33)$ & $(.28)$ & $(.34)$ & $(.34)$ \\
\hline \multicolumn{2}{|l|}{$\begin{array}{l}\% \text { of total person-year } \\
\text { observations contributed }\end{array}$} & .31 & .25 & .44 \\
\hline
\end{tabular}


Table 3. Effect of R etirement on Life Satisfaction, O.L.S. and Fixed Effects E stimates.

\section{O.L.S Estimates}

\begin{tabular}{|c|c|c|c|c|}
\hline V ariable & Depressed & Lonely & $\underline{\text { Depressed }}$ & Lonely \\
\hline \multirow[t]{2}{*}{ R etired } & .05 & .03 & 0.004 & 0.003 \\
\hline & $(.01)$ & $(.01)$ & $(.002)$ & $(0.002)$ \\
\hline \multirow[t]{2}{*}{ Constant } & .33 & .46 & & \\
\hline & (.1) & $(.09)$ & & \\
\hline \multirow[t]{2}{*}{ W hite? } & -.05 & -.03 & & \\
\hline & $(.01)$ & $(.01)$ & & \\
\hline \multirow[t]{2}{*}{ Schooling < 12 Y rs } & .06 & .05 & & \\
\hline & $(.01)$ & $(.01)$ & & \\
\hline \multirow[t]{2}{*}{ Schooling $>12$ Y rs } & -.002 & -.02 & & \\
\hline & $(.009)$ & $(.01)$ & & \\
\hline \multirow{2}{*}{ Age } & -.001 & -.002 & & \\
\hline & $(.001)$ & $(.001)$ & & \\
\hline \multirow[t]{2}{*}{ M arried } & -.08 & -.2 & -.12 & -.16 \\
\hline & $(.01)$ & $(.01)$ & $(.02)$ & $(.02)$ \\
\hline \multirow[t]{2}{*}{ Health "Excellent" } & -.09 & -.06 & -.1 & -.1 \\
\hline & $(.01)$ & $(.01)$ & $(.01)$ & $(.01)$ \\
\hline \multirow[t]{2}{*}{ 1990's Observation } & -.08 & -.03 & & \\
\hline & $(.01)$ & $(.01)$ & & \\
\hline Data Source Indicator & Yes & Yes & & \\
\hline $\mathrm{R}^{2}$ & .07 & .08 & .04 & .03 \\
\hline
\end{tabular}

The are performed on a combined sample which uses multiple years data from the National Longitudinal Survey of M en, the Health and Retirement Study, and the Survey of Asset and Health Dynamics among the Oldest Old. All regressions control for the number of children and residence in the South. People in their 60's are between 60 and 69 in the survey year; people in their 70's are between 70 and 79. See text for further clarification. (Standard Errors in Parentheses). 
Table 4. Effect of Social Security Eligibility, and of Changes in Social Security Rules Over Time on R etirement: First Stage Regressions.

\begin{tabular}{|c|c|c|c|c|}
\hline Variable & $\begin{array}{c}\text { Est. } \\
\text { (Std.Error) }\end{array}$ & $\begin{array}{c}\text { Est. } \\
\text { (Std.Error) }\end{array}$ & $\begin{array}{c}\text { Est. } \\
\text { (Std.Error) }\end{array}$ & $\begin{array}{c}\text { Est. } \\
\text { (Std.Error) }\end{array}$ \\
\hline \multirow[t]{2}{*}{ Age } & .32 & .2 & .16 & .21 \\
\hline & $(.02)$ & $(.01)$ & $(.04)$ & $(.04)$ \\
\hline \multirow[t]{2}{*}{ Age-Squared } & -.002 & -.002 & -.001 & -.001 \\
\hline & $(.0001)$ & $(.001)$ & $(.002)$ & $(.0002)$ \\
\hline \multirow[t]{2}{*}{ A fter-A mendment } & .06 & -.42 & .09 & -.08 \\
\hline & $(.02)$ & $(.2)$ & $(.02)$ & (.03) \\
\hline \multirow[t]{2}{*}{ A ge* A fter-A mendment } & & .007 & & \\
\hline & & $(.002)$ & & \\
\hline \multirow[t]{2}{*}{ A ge $>61$} & & & .08 & .04 \\
\hline & & & $(.02)$ & $(.02)$ \\
\hline \multirow[t]{2}{*}{ A ge $>64$} & & & .08 & .04 \\
\hline & & & $(.08)$ & $(.02)$ \\
\hline \multirow[t]{2}{*}{ A ge $>69$} & & & -.07 & -.08 \\
\hline & & & $(.02)$ & $(.03)$ \\
\hline \multirow{2}{*}{ A ge $>71$} & & & -.002 & -.04 \\
\hline & & & $(.02)$ & (.03) \\
\hline A ge $>61 *$ A fter- & & & & .03 \\
\hline A mendment & & & & $(.02)$ \\
\hline A ge $>64 * A$ fter- & & & & .07 \\
\hline A mendment & & & & $(.02)$ \\
\hline A ge> $69 *$ A fter- & & & & .08 \\
\hline A mendment & & & & $(.03)$ \\
\hline A ge> $71 *$ A fter- & & & & .03 \\
\hline A mendment & & & & (.03) \\
\hline F - (excluded instruments) & & 7.08 & 15.57 & 11.18 \\
\hline$R^{2}$ & .15 & & .17 & .18 \\
\hline
\end{tabular}

Data are from multiple W aves of the NLS-M M, HRS and A head, drawn from the early 1980's and early 1990's. Each regression includes a dummy variable which is a data set indicator, a race indicator, a marital status indicator; an indicator for poor health; and a measure for completed schooling. The men in these regressions are between 60 and 79 in the year they are observed. 
Table 5. E ffect of R etirement on Life Satisfaction, First Set of TSLS E stimates.

\begin{tabular}{|c|c|c|c|}
\hline (I) & (II) & $(\mathrm{III}) *$ & (IV) \\
\hline $\begin{array}{l}\text { Dummies for A ge G reater } \\
\text { than } 61,64,69 \text { and } 70\end{array}$ & $\begin{array}{l}\text { (I) + Dummies for Age } \\
\text { Greater than } 61,64,69 \text { and } \\
70 \text {, each with Dummy for } \\
\text { Period A fter A mendment }\end{array}$ & $\begin{array}{l}\text { Dummies for A ge G reater } \\
\text { than } 61,64,69 \text { and } 70 \text {, each } \\
\text { Interacted with Dummy for } \\
\text { Period A fter A mendment }\end{array}$ & $\begin{array}{l}\text { A ge Dummies * D ummy for } \\
\text { Time Period A fter A mendment }\end{array}$ \\
\hline
\end{tabular}

\section{Entire Sample}

Depressed?

Lonely?

Only 60-yr olds

Depressed?

Lonely?

Only 70-yr olds

$$
\begin{array}{ll}
-.1 & (.08) \\
-.21 & (.09)
\end{array}
$$

$-.2(.08)$

-.11 (.09)

. $.2(.17)$

$\begin{array}{ll}-.13 & (.07) \\ -.25 & (.08)\end{array}$

$-.13(.06)$

$-.18(.08)$

$-.1 \quad(.08)$

-.18 (.1)

$\begin{array}{ll}-.18 & (.15) \\ -.28 & (.15)\end{array}$

$-.16 \quad(.11)$

-.19 (.09)

$-.12 \quad(.08)$

$\begin{array}{lll}-.27 \quad(.16) & 0\end{array}$
$-.06(.03)$

$-.15(.05)$

-.13 (.06)

-.18 (.08)

$-.04 \quad(.03)$

$-.07 \quad(.03)$

The regressions are performed on a combined sample which uses multiple years data from the $N$ ational Longitudinal Survey of M en, the Health and R etirement Study, and the Survey of A sset and Health Dynamics among the Oldest Old. All structural well being equations control for race, years of schooling, age, age-squared, marital status, self-rated health, the source of the data; a time trend, number of children and residence in the South. The regression in column (III) adds the four minimum age indicators to the well being equation. People in their 60's are between 60 and 69 in the survey year; people in their 70's are between $\mathbf{7 0}$ and 79. See text for further clarification. Standard errors in Parentheses. The regressions which are restricted to people of particular ages only include minimum age dummy variables which can vary for the particular age group. 
Table 6. E ffect of Previous Mandatory R etirement R ule Coverage on Later R etirement: First Stage Regressions.
(I)
(II)

\section{Variable}

Mandatory Retirement Plan in 1969

White?

Married with Spouse P resent

Rate Physical Health "Excellent"

\begin{tabular}{l}
\hline$R^{2}$ \\
Data are from 1969, 1981 and 1983 Waves of the National Longitudinal Survey of M ature \\
Men. The regressions use the 1369 observations for which there are non-missing \\
information. See text for further explanation. (Standard Errors in parentheses).
\end{tabular}


Table 7. Effect of R etirement Status on W ell B eing, Second set of TSLS Estimates.

\begin{tabular}{|c|c|c|c|c|}
\hline & \multicolumn{2}{|c|}{ (I) } & \multicolumn{2}{|c|}{ (II) } \\
\hline & Depressed & Lonely & Depressed & Lonely \\
\hline \multirow[t]{2}{*}{ R etired? } & -.19 & -.16 & -.16 & -.14 \\
\hline & $(.08)$ & $(.09)$ & $(.07)$ & $(.07)$ \\
\hline \multirow[t]{2}{*}{ White? } & & & -.06 & -.05 \\
\hline & & & $(.02)$ & $(.02)$ \\
\hline \multirow[t]{2}{*}{ Schooling $<12$ Y ears } & & & .07 & .06 \\
\hline & & & $(.02)$ & $(.02)$ \\
\hline \multirow[t]{2}{*}{ Schooling > 12 Y ears } & & & .01 & -.01 \\
\hline & & & $(.02)$ & $(.02)$ \\
\hline \multirow[t]{2}{*}{ A ge } & & & .005 & .01 \\
\hline & & & $(.004)$ & $(.003)$ \\
\hline \multirow[t]{2}{*}{ M arried } & & & -.08 & -.15 \\
\hline & & & $(.024)$ & $(.02)$ \\
\hline \multirow[t]{2}{*}{ Resides in South } & & & .05 & .02 \\
\hline & & & $(.02)$ & $(.01)$ \\
\hline \multirow[t]{2}{*}{ Health "Excellent" } & & & -.13 & -.09 \\
\hline & & & $(.017)$ & $(.01)$ \\
\hline$R^{2}$ & .03 & .05 & .04 & .06 \\
\hline
\end{tabular}


Figure 1. Retirement Status in 1980's, by Age

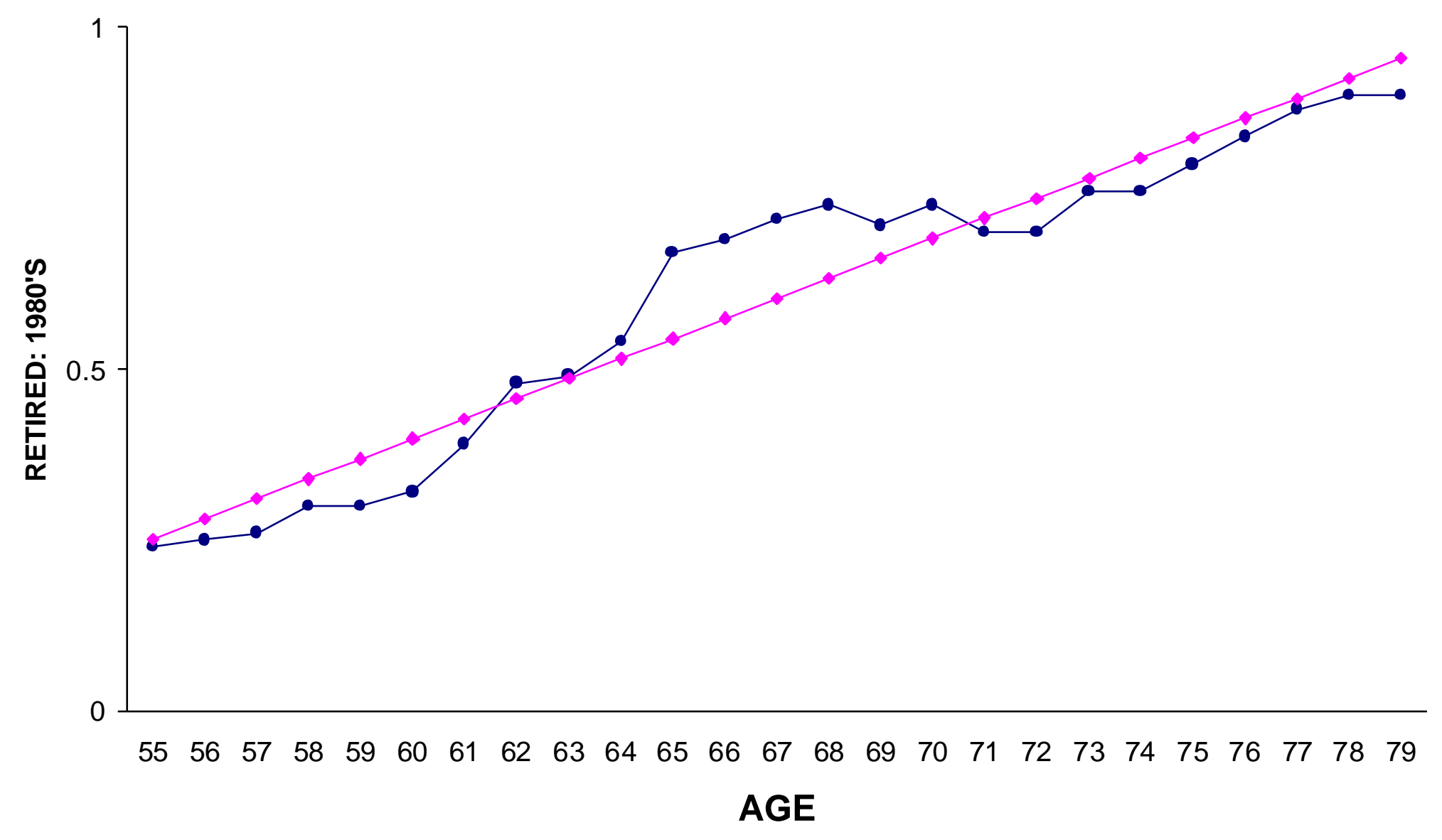

$\multimap$ Actual $\multimap$ Predicted 
Figure 2. Retirement Status in 1990's, by Age

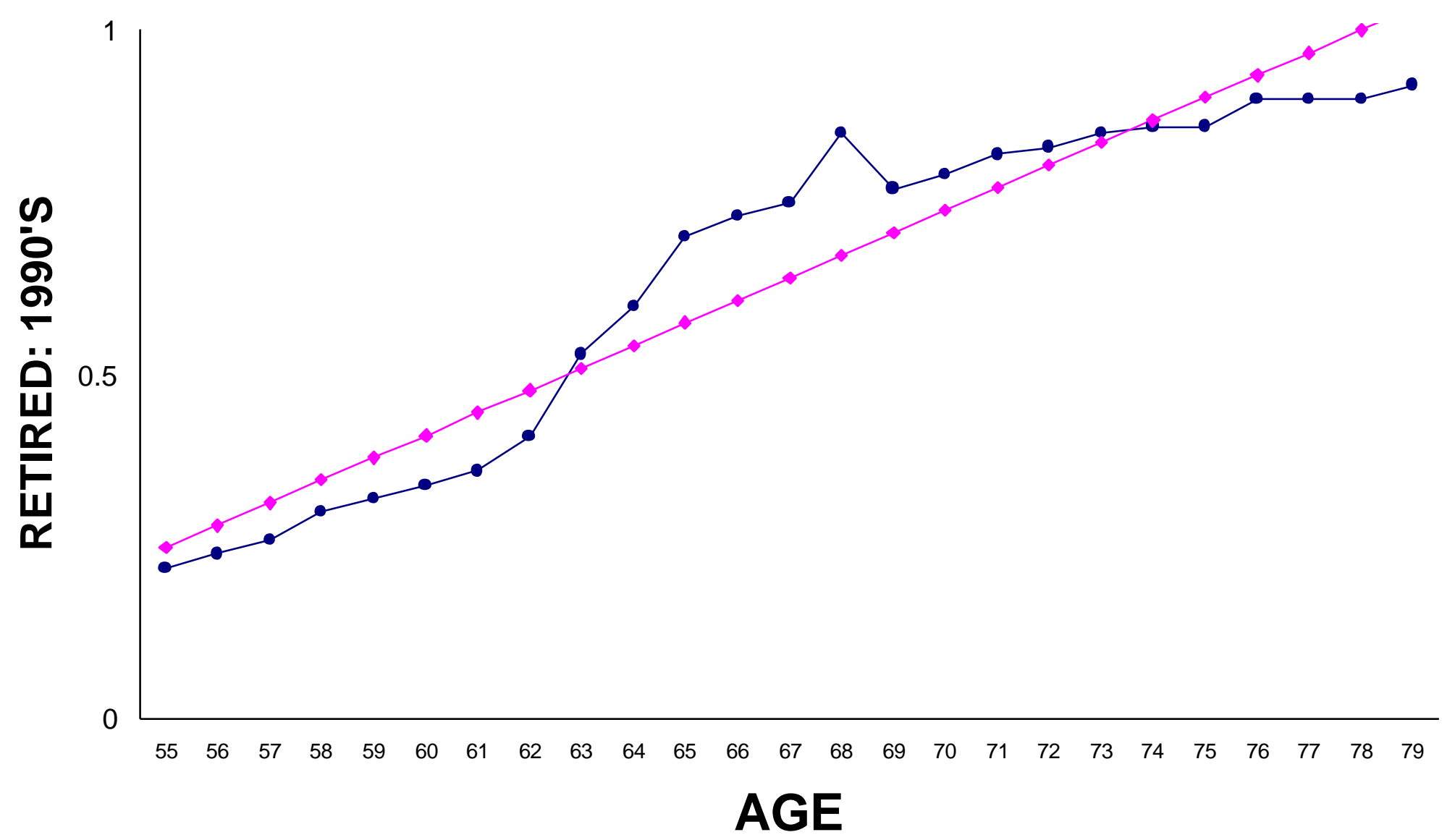

$\multimap$ Actual $\rightarrow$ Predicted 